\title{
Effect of Pre/Postconditioning at Temporary Clipping
}

\author{
M Ozgur TASKAPILIOGLU¹, Tugba MORALI GULER', Gokhan OCAKOGLU², Ender KORFALI
}

${ }^{1}$ Uludag University, School of Medicine, Department of Neurosurgery, Bursa, Turkey

${ }^{2}$ Uludag University, School of Medicine, Department of Biostatistics, Bursa, Turkey

\section{ABSTRACT}

\begin{abstract}
Intracranial aneurysms and their treatment is one of the leading problems of neurosurgery that create high mortality and morbidity. The technique of safe clipping is as generally used depends on the temporary occlusion of the cerebral vasculature during surgery. However, there is no exact data about temporary clipping or timing of this procedure.
\end{abstract}

Preconditioning by exposure to sublethal hypoxic stress, hours or days before severe hypoxia, decreases cell death, and this resistance of the brain to injury is known as ischemic tolerance. Brief alternating periods of reperfusion-reocclusion at the beginning of reperfusion is defined as postconditioning. Cerebral ischemic pre/postconditioning protects against stroke, but is clinically feasible only when the occurrence of stroke is predictable.

Brief, repetitive occlusion and release of the main trunk of a vessel during early aneurysm surgery or before long-lasting temporary artery occlusion may protect the brain against later possible vasospasm/ischemia.

KEYWORDS: Aneursym, Postconditioning, Preconditioning, Temporary clipping

\section{INTRODUCTION}

"that which does not kill us makes us stronger" Nietzsche

Intracranial aneurysms and its treatment is still one of the leading problems of neurosurgery. Modern medical era has developed different treatment modalities but the importance of surgery still continues. The technique of safe clipping as generally used depends on the temporary occlusion of the cerebral vasculature during surgery. It may lessen the risk of intraoperative aneurysm rupture and also allows evacuation of intramural calcification and thrombosis before definitive clipping in large aneurysms.

Elective temporary occlusion in the treatment of intracranial aneurysms was first performed by Jefferson in 1928. He used a modified Michel clip for proximal vessel control. In 1947, Henry Schwartz manufactured a clip that could be applied with a modified uterine forceps for the purpose of temporary vessel occlusion with the help of George Bishop (55). In 1957, a modified Cairns clip was used in two cases of aneurysm by Gibbs (55). Temporary clamping and moderate hypothermia in the treatment of aneurysms were reported by Suzuki et al. in 1969. The authors pointed that intermittent reperfusion allowed prolongation of the total time of temporary occlusion (52). After the late 1970s, there were an increasing number of reports on the use of precautionary temporary artery occlusion in the surgical management of giant aneurysms $(4,20,51,53)$. Ljunggren et al. reported that occlusion was well tolerated at the middle cerebral artery (MCA) for up to 20 minutes in 1983 (31). The routine use of both proximal and distal temporary clipping was pioneered by Suzuki (8). After Ausman's paper in 1985 , many articles have reported the routine use of temporary artery occlusion in large series of patients $(2,8,44)$.

However, there is no agreement on the time of temporary clipping and its application to protect the patient from focal cerebral ischemia and associated neurologic injury $(8,13,21$, 28, 38, 44, 55). 
Intraoperative aneurysm rupture and ischemia due to prolonged temporary clipping are direct causes of mortality and morbidity of aneurysm surgery $(3,9,14,59)$. However, sometimes prolonged occlusion is mandatory for complete clipping. The period of stroke-free temporary clipping varies depending on the clinical factors and the occluded vessel (13).

Monitoring of brain tissue oxygen concentration $\left(\mathrm{PtiO}_{2}\right)$ has been used to detect changes in brain oxygenation due to temporary clipping (9). Cerejo et al. showed that there were significant decrease $(20 \%$ or more, compared with the basal value) in $\mathrm{PtiO}_{2}$ values after temporary clipping (9).

Motoyama et al. studied the reliability of combined use of transcranial and direct cortical motor evoked potential (MEP) monitoring during unruptured aneurysm surgery (35). Decrease or disappearance of direct MEP waves were recovered immediately after re-application of the clip and release of the temporary clip and they showed that combined transcranial and direct cortical MEP recording may improve the feasibility and reliability of MEP monitoring during unruptured aneurysm surgery (35).

Ischemic events can occur even in cases of aneurysm surgery. Organisms respond with protective mechanisms to recurrent insults and this resistance of the brain to ischemic injury is known as ischemic tolerance (IT). IT induced by several paradigms represents an important phenomenon of central nervous system (CNS) adaptation to sublethal short-term ischemia (17).

Ischemic preconditioning (IP) was first introduced by Murry (36) in the heart and later Schurr et al. and Kitagawa et al. worked on this subject in the brain $(26,47)$. The molecular mechanisms underlying IT are not yet fully understood. Many experimental and clinical studies have been performed to understand the nature of the neuroprotective mechanism regarding extreme metabolic stress, such as hypoxia/ anoxia/ ischemia $(25,41)$. Global ischemia, focal ischemia, cerebral hypoxia, cortical spreading depression, hypo/hyperthermia, heat shock and various pharmacological agents can play a role in preconditioning (30). In 1991, Burda et al. showed that graded postischemic reoxygenation could be used as a neuroprotective tool to prevent secondary postischemic damage in nervous tissue (6). Later Danielisova et al. documented that the duration of the sublethal ischemic episode (for 3-8 min) and the time that had elapsed between the second ischemia are important (10). After induced IT by IP, SOD and CAT were significantly increased after 5 hours and 1 and 2 days of reperfusion (11).

Older patient age, poor grade of hemorrhage, location of aneurysm, size of aneurysm, and the risk of intraoperative aneurysm rupture are other factors that affect the potential risk of stroke (13). Ferch et al. observed a trend for an increased incidence of stroke in patients in whom temporary vessel occlusion was performed for more than 10 minutes in their retrospective analysis and pointed that early surgery, and the use of single prolonged clip placement rather than repeated shorter episodes were associated with a higher risk of stroke (13). Contrary to other authors, Ferch et al. concluded that intraoperative aneurysm rupture did not affect stroke risk and only poorer clinical grade and increasing age were significantly associated with symptomatic stroke risk (13).

There are two concepts based on experimental studies. Temporary or continuous occlusion of vessels can be used to protect the brain from ischemia $(12,16,38,49)$. The temporary occlusion times were longer in the studies in which the rate of stroke was lower when continuous compared with intermittent occlusion was performed $(13,38,44)$.

In a series of 100 normothermic, normotensive patients Samson et al. suggested that 15 to 20 minutes was the maximum period of occlusion that could be safely sustained by the help of etomidate protection. They found that 31 minutes was the cut off value for clinical and radiological evidence of cerebral infarction (44). Evoked potential failure has been used as an indicator of dense ischemia in cerebral tissue by several authors $(15,34)$. Sensory evoked potentials were lost approximately 9 minutes after temporary clipping. If recirculation was reestablished within 20 minutes of the occlusion, the rate of clinical sequelae was very low (34).

Intraoperative monitoring of cortical blood flow has also been used to define the safe limits of temporary vessel occlusion in the literature (39).

Mild hypothermia and mannitol administration was used to prevent cerebral infarction (38). Ogilvy et al. used intravenous mannitol and induced systemic hypertension and mild hypothermia prior to and during planned temporary vessel occlusion. They concluded that stroke develops when temporary clipping stands more than 20 minutes and intraoperative aneurysm rupture was very significantly associated with stroke outcome (38). There is a 10-minute time gap of infraction times between Ogilvy and Samson. This time difference might be because one group had hypothermia and hypertension induction while Samson, et al. used the normothermic, normotensive anesthetic technique $(38,44)$.

Protection of cooling in ischemic conditions is a welldocumented subject in the literature, both in the clinical setting and animal studies (18, 19, 22, 24, 27). Mack et al. showed that longest occlusion times could be achieved by using a combination of global deep hypothermia and cardiac standstill but had a high mortality rate of $12 \%$ at one month and fair or poor outcome rate of $20 \%$ (32).

The Intraoperative Hypothermia for Aneurysm Surgery Trial (IHAST) was a randomized trial of mild systemic hypothermia $\left(33^{\circ} \mathrm{C}\right)$ in 1000 patients undergoing surgery to treat an acutely ruptured intracranial aneurysm. The study showed that hypothermia did not significantly affect neurologic or neuropsychologic outcomes. However, supplemental drug administration was not considered in the study $(21,56)$. Todd et al. pointed out that patients who had temporary clip durations greater than or equal to $20 \mathrm{~min}$ had less favorable outcomes but they did not mention the indications of temporary clipping (21).

Aneurysms that were located on arteries with perforating vessel segments appeared to have poor tolerance for long 
occlusion times $(28,44)$. For example, Samson et al. showed infarction rates of $41 \%$ for the basilar group and $7 \%$ for the internal carotid artery (44). Lavine et al. performed an intermittent temporary clip application with no standardization for the number or duration of reperfusion episodes and showed that infarction rates from undergoing intermittent temporary clip application was lower than the continuous episode of ischemia, which was a contradiction of the results of Ogilvy et al. $(28,38)$.

Five minutes of reperfusion after every 10 minutes of ischemia produced by intraluminal occlusion of the MCA in rats resulted in significantly smaller infarction volumes compared to continuous ischemia as demonstrated by Goldman et al. (16). A decrease in infarction size and decreased cortical neuronal damage have shown by Steinberg et al. in another model of interrupted focal ischemia (49). However, there are also conflicting results with the damage of reperfusion in different animal models $(5,46,57)$.

One of the main concerns about intermittent clip applications was reperfusion injury that was discovered to be the significant component of ischemic injury $(33,48)$.

Selman et al. showed that intermittent or continuous occlusion was not important for the volume of infarction. They compared the infarct volumes with intermittent and continuous occlusion in normotensive and spontaneously hypertensive rats and concluded that spontaneously hypertensive rats had a greater volume of infarction than normotensive rats independent of the occlusion type (46).

Group comparisons of Glasgow Coma Scale (GCS) and Glasgow Outcome Scale (GOS) scores were performed by using the Kruskal-Wallis test. Subgroup analysis for multiple comparisons was performed by using the Mann-Whitney test with Bonferroni correction. Sex was compared among groups by the chi-square test. Correlation analysis was performed for examining the relationship between GCS and GOS scores and the Spearman correlation coefficient was computed. $\mathrm{P}<0.05$ was set at statistical significance and SPSS 20.0 was used for performing statistical analyses.

In the analysis of our 544 aneurysm series, there was no significant difference with respect to distribution of age between groups $(p=0.285)$. There was a significant difference for sex between the groups $(p<0.001)$. In subgroup analysis, there was a significant difference between Gr1 and Gr2 $(p<0.001)$, Gr1 and Gr4 ( $p=0.015)$, Gr2 and Gr3 ( $p<0.001)$, Gr2 and Gr5 ( $p<0.001), G r 3$ and Gr4 ( $p=0.009), G r 4$ and Gr5 $(p=0.005)$ and $\operatorname{Gr} 5$ and $\operatorname{Gr} 6(p=0.017)$ but no difference was found between $\mathrm{G} 1$ and $\mathrm{Gr} 3(\mathrm{p}=0.434)$, Gr1 and $\operatorname{Gr} 5(p=0.228)$, Gr1 and Gr6 ( $p=0.094)$, Gr2 and Gr4 ( $p=0.166), G r 2$ and Gr6 $(p=0.147), \operatorname{Gr} 3$ and $\operatorname{Gr} 5$ ( $p=0.845), \operatorname{Gr} 3$ and Gr6 ( $p=0.052), \operatorname{Gr} 4$ and $\operatorname{Gr} 6(p=0.069)$ (Table I). No difference was found between the groups according to GCS scores $(p=0.295)$, but there was a significant difference between the groups according to GOS scores $(p=0.010)$. A significant difference was found between Group 1 and Group 5 with respect to subgroup analysis $(p=0.003)$ and the GOS score of group 5 was higher than Group 1 (Table II).

Comparisons according to GCS and GOS scores of the groups are given in Table III. There was no difference between the temporary and direct clipped-groups according to the values of GCS and GOS (respectively $p=0.188, p=0.162$ ). A significant relationship between GCS and GOS scores was found according to the results of the correlation analysis $(r=0.37 ; p<0.001)$.

Transient ischemic events contribute to the development of stroke as tissue injury during the ischemic period and as reperfusion injury. Free oxygen radicals play an important role in postischemic tissue injury (58).

Repetitive interruption of blood flow at the onset of tissue perfusion after an ischemic period has been defined as postconditioning (61). The effectiveness of postconditioning in different organs such as the heart, kidney, muscles, skin, and intestinal mucosa were studied (30). Zhao et al. showed that three cycles of 30 seconds interruptions of blood flow in the dog coronary arteries following 60 minutes of ischemia decreased the infarct area from a mean of $47 \%$ to $11 \%$ (61). Many experimental studies have proven the neuroprotective effects of ischemic postconditioning $(6,54,62,63)$. Hippocampal CA1 neuronal protection by postconditioning was shown by Burda and Danielisová in two different models $(7,11)$. Jiang and Turkkan proved the value of postconditioning in spinal cord injury models $(23,58)$.

Taşkapılıoğlu et al. showed that preconditioning, postconditioning, and pre/post conditioning have preventive effects

Table I: Comparison of Groups According to Demographic Variables. $\mathrm{Gr}_{1}$ : MCA, $\mathrm{Gr}_{2}$ : ACoA, $\mathrm{Gr}_{3}$ : $\mathrm{Pcomm}_{4}$, $\mathrm{Gr}_{4}$ : $\mathrm{Gr}_{5}$ : other Localisations, $\mathrm{Gr}_{6}$ : Multiple

\begin{tabular}{|c|c|c|c|c|c|c|c|c|}
\hline & & $\mathrm{Gr}_{1}(\mathrm{n}=147)$ & $\mathrm{Gr}_{2}(\mathrm{n}=192)$ & $\mathrm{Gr}_{3}(\mathrm{n}=59)$ & $\mathrm{Gr}_{4}(\mathrm{n}=5)$ & $\mathrm{Gr}_{5}(\mathrm{n}=75)$ & $\mathrm{Gr}_{6}(\mathrm{n}=66)$ & $p$-value \\
\hline Sex & $\mathrm{f} / \mathrm{m}$ & $85 / 62$ & $68 / 124$ & $38 / 21$ & $0 / 5$ & $44 / 21$ & $30 / 36$ & $<0.001$ \\
\hline \multirow{4}{*}{ Age } & Median & 50.5 & 50 & 51 & 46 & 49 & 53 & \multirow{4}{*}{0.285} \\
\hline & Min.-Max. & $20-84$ & $12-85$ & $25-85$ & $42-65$ & $16-75$ & $20-74$ & \\
\hline & Mean & 51.78 & 49.97 & 52.77 & 48.80 & 47.38 & 52.03 & \\
\hline & St.Dev. & 11.22 & 12.12 & 13.41 & 9.52 & 13.64 & 11.39 & \\
\hline
\end{tabular}

MCA: middle cerebral artery, ACoA: anterior communicating artery, Pcomm: posterior communicating artery, BA: basilar artery, f: female, m: male. 
Table II: Comparisons between Groups Based on GCS and GOS Scores

\begin{tabular}{|c|c|c|c|c|c|c|c|c|}
\hline & & $\mathrm{Gr}_{1}(\mathrm{n}=147)$ & $\mathrm{Gr}_{2}(\mathrm{n}=192)$ & $\mathrm{Gr}_{3}(\mathrm{n}=59)$ & $\mathrm{Gr}_{4}(\mathrm{n}=5)$ & $\mathrm{Gr}_{5}(\mathrm{n}=75)$ & $\mathrm{Gr}_{6}(\mathrm{n}=66)$ & $\mathrm{p}$-value \\
\hline \multirow{4}{*}{ ల్ } & Median & 15 & 15 & 15 & 15 & 15 & 15 & \multirow{4}{*}{0.295} \\
\hline & Min.-Max. & $4-15$ & $5-15$ & $7-15$ & $8-15$ & $7-15$ & $4-15$ & \\
\hline & Mean & 14.01 & 14,55 & 14.56 & 13.60 & 14.69 & 14.35 & \\
\hline & St.Dev. & 2.43 & 1.21 & 1.28 & 3.13 & 1.04 & 1.84 & \\
\hline \multirow{4}{*}{$\begin{array}{l}\mathscr{D} \\
\text { O) }\end{array}$} & Median & 5 & 5 & 5 & 3 & 5 & 5 & \multirow{4}{*}{0.010} \\
\hline & Min.-Max. & $1-5$ & $1-5$ & $1-5$ & $1-5$ & $1-5$ & $1-5$ & \\
\hline & Mean & 3.99 & 4.22 & 4.17 & 3.00 & 4.57 & 4.21 & \\
\hline & St.Dev. & 1.50 & 1.28 & 1.25 & 1.58 & 1.02 & 1.22 & \\
\hline \multicolumn{9}{|c|}{ Pairwise Comparisons for GOS $\left(a^{*}=0.003\right)$} \\
\hline \multicolumn{3}{|c|}{$\mathrm{Gr}_{1}-\mathrm{Gr}_{2}: \mathrm{p}=0.328$} & \multicolumn{3}{|c|}{$\mathrm{Gr}_{2}-\mathrm{Gr}_{3}: \mathrm{p}=0.384$} & & \multicolumn{2}{|c|}{$\mathrm{Gr}_{3}-\mathrm{Gr}_{5}: \mathrm{p}=0.004$} \\
\hline \multicolumn{3}{|c|}{$\mathrm{Gr}_{1}-\mathrm{Gr}_{3}: \mathrm{p}=0.941$} & \multicolumn{3}{|c|}{$\mathrm{Gr}_{2}-\mathrm{Gr}_{4}: \mathrm{p}=0.029$} & & \multicolumn{2}{|c|}{$\mathrm{Gr}_{3}-\mathrm{Gr}_{6}: \mathrm{p}=0.643$} \\
\hline \multicolumn{3}{|c|}{$\mathrm{Gr}_{1}-\mathrm{Gr}_{4}: \mathrm{p}=0.085$} & \multicolumn{3}{|c|}{$\mathrm{Gr}_{2}-\mathrm{Gr}_{5}: \mathrm{p}=0.013$} & & \multicolumn{2}{|c|}{$\mathrm{Gr}_{4}-\mathrm{Gr}_{5}: \mathrm{p}=0.016$} \\
\hline \multicolumn{3}{|c|}{$\mathrm{Gr}_{1}-\mathrm{Gr}_{5}: \mathrm{p}=0.003$} & \multicolumn{3}{|c|}{$\mathrm{Gr}_{2}-\mathrm{Gr}_{6}: \mathrm{p}=0.820$} & & \multicolumn{2}{|c|}{$\mathrm{Gr}_{4}-\mathrm{Gr}_{6}: \mathrm{p}=0.073$} \\
\hline \multicolumn{3}{|c|}{$\mathrm{Gr}_{1}-\mathrm{Gr}_{6}: \mathrm{p}=0.563$} & \multicolumn{3}{|c|}{$\mathrm{Gr}_{3}-\mathrm{Gr}_{4}: \mathrm{p}=0.084$} & & \multicolumn{2}{|c|}{$\mathrm{Gr}_{5}-\mathrm{Gr}_{6}: \mathrm{p}=0.023$} \\
\hline
\end{tabular}

Table III: Comparisons Between GCS and GOS Scores of Groups: 1 Intermitant Clip; 2 Direct Clip

\begin{tabular}{ccc}
\hline clip & GCS & GOS \\
\hline $1(n=213)$ & $15(5-15)$ & $5(1-5)$ \\
\hline $2(n=331)$ & $15(4-15)$ & $5(1-5)$ \\
\hline$p$-value & 0.188 & 0.162 \\
\hline
\end{tabular}

against cerebral ischemia in a rat focal cerebral model of ischemia that was induced by suture occlusion of the middle cerebral artery (54).

Ischemic postconditioning mechanisms underlying neuroprotection were thought to be similar to those underlying cardioprotection, which involves decreased neutrophil accumulation and endothelial dysfunction, decreased mitochondrial permeability, decreased apoptotic cell death and phosphatidylinositol 3-kinase pathway activation (63).

Xing et al. reported that six cycles of middle cerebral artery occlusion 30 seconds apart produced neuroprotection via inhibition of apoptosis (60). Danielisova et al. reported that delayed postconditioning, when applied 48 hours after ischemia, provides neuroprotection (11).

Nemethova et al. used a 2 or 3 days of reperfusion followed by 5 minutes of ischemia and another 1 day of reperfusion for detecting the immunoreactivity of antioxidant enzymes and proteins that were related to apoptosis in postconditioning. They showed that the increased expression of antioxidant enzymes and prevention of ischemia-induced increase of the pro-apoptotic protein Bax (37).
There are also growing data about ischemic preconditioning indicating that it not only has a protective effect on the same tissue, but can also express its protection in remote tissues and organs, known as remote ischemic postconditioning (IPC) (29).

There is little knowledge on the mechanism of postconditioning effect. Improvement at the cerebral blood flow, prevention of cytochrome c translocation, activation of protein kinase Akt., and activation of the phosphoinositide 3-kinase-linked pathway have been described in animal models (30). Ren et al. showed that delayed postconditioning with 6 cycles of 15 minutes occlusion/15 minutes release of the ipsilateral common carotid arteries protected against focal ischemia in a rat model (42).

Angina prior to myocardial infarction resulted in smaller infarct size and has been shown to be protective both in the animal model and human studies. (43).

Upregulation of endogenous pathways by stimuli causing trauma in the central nervous system may lead to neuroprotection by increasing the endurance to ischemia or trauma (54). Timely opening of the occluded vessels will provide reperfusion. However, reperfusion injury that may take place through overproduction of free radicals is the pending threat (54).

Cerebral ischemic pre/postconditioning protects against stroke, but is clinically feasible only when the occurrence of stroke is predictable. Stroke development in neurosurgical practice is commonly seen during aneurysm surgery while utilizing temporary clip application. Ischemic tolerance is determined by both the degree of the perfusion defect, and 
the duration of ischemia. Prompt recanalisation with shorter duration of ischemic insult will be more beneficial for the viability of the neural tissues $(45,54)$.

Ischemic preconditioning was first shown to develop days after the first insult. However, Perez-Pinzon et al. then reported that a short time, like 30 minutes, subsequent to the injury was enough for the development of the expected protective effect of the insult (40). A rat model with 2 hours occlusion performed 24 hours after 10 minutes of preconditioning showed a decreased cerebral infarct volume (54).

Similar pathways and molecules take place in pre and postconditioning but their roles and timing are different in each condition (50). Reperfusion injury is expressed as endothelial and microvascular dysfunction, impaired blood flow, metabolic dysfunction, cellular necrosis, and apoptosis (1).

There are some limitations in our series. First, this is a retrospective analysis. There was no statistical difference between intermittent and direct clipped groups in our series but generally temporary clips were used for ruptured and amorphous aneurysms.

In conclusion, repetitive occlusion and release of the main trunk of a vessel during early aneurysm surgery or before long-lasting temporary artery occlusion may protect the brain against later possible vasospasm/ischemia. Studies on the precise temporal characteristics of pre- and postconditioning, or both, in the brain and determination of the presence of a therapeutic role are very important.

\section{REFERENCES}

1. Alkan T: Neuroprotective effects of ischemic tolerance (preconditioning) and postconditioning. Turk Neurosurg 19:406412, 2009

2. Ausman JI, Diaz FG, Malik GM, Fielding AS, Son CS: Current management of cerebral aneurysms: Is it based on facts or myths? Surg Neurol 24:625-635, 1985

3. Batjer H, Samson D: Intraoperative aneurysmal rupture: Incidence, outcome, and suggestions for surgical management. Neurosurgery 18:701-702, 1986

4. Batjer HH, Frankfurt Al, Purdy PD, Smith SS, Samson DS: Use of etomidate, temporary arterial occlusion, and intraoperative angiography in surgical treatment of large and giant cerebral aneurysms. J Neurosurg 68:234-240, 1988

5. Bell BA, Symon L, Branston NM: CBF and time thresholds for the formation of ischemic cerebral edema, and effect of reperfusion in baboons. J Neurosurg 62:31-41, 1985

6. Burda J, Marsala M, Radonak J, Marsala J: Graded postischemic reoxygenation ameliorates inhibition of cerebral cortical protein synthesis in dogs. J Cereb Blood Flow Metab 11:1001-1006, 1991

7. Burda J, Matiasova M, Gottlieb M: Evidence for a role of second pathophysiological stress in prevention of delayed neuronal death in the hippocampal CA1 region. Neurochem Res 30:1397-1405, 2005

8. Charbel FT, Ausman JI, Diaz FG, Malik GM, Dujovny M, Sanders $\mathrm{J}$ : Temporary clipping in aneurysm surgery: Technique and results. Surg Neurol 36:83-90, 1991
9. Cerejo A, Silva PA, Dias C, Vaz R: Monitoring of brain tissue oxygenation in surgery of middle cerebral artery incidental aneurysms. Surg Neurol Int 2:37, 2011

10. Danielisova V, Gottlieb M, Nemethova M, Burda J: The effect of preconditioning on the iron deposition after transient forebrain ischemia in rat brain. Arch Ital Biol Mar 142:87-94, 2004

11. Danielisova V, Nemethova M, Gottlieb M, Burda J: Changes of endogenous antioxidant enzymes during ischemic tolerance acquisition. Neurochem Res 30:559-565, 2005

12. David CA, Prado R, Dietrich WD: Cerebral protection by intermittent reperfusion during temporary focal ischemia in the rat. J Neurosurg 85:923-928, 1996

13. Ferch R, Pasqualin A, Pinna G, Chioffi F, Bricolo A: Temporary arterial occlusion in the repair of ruptured intracranial aneurysms: An analysis for risk factors for stroke. J Neurosurg 97:836 - 842, 2002

14. Fergusen S, Macdonald RL: Predictors of cerebral infarction in patients with aneurysmal subarachnoid hemorrhage. Neurosurgery 60:658-667, 2007

15. Friedman WA, Chadwick GM, Verhoeven FJS, Mahla M, Day AL: Monitoring of somatosensory evoked potentials during surgery for middle cerebral artery aneurysms. Neurosurgery 29:83-88, 1991

16. Goldman MS, Anderson RE, Meyer FB: Effects of intermittent reperfusion during temporal focal ischemia. J Neurosurg 77: 911916, 1992

17. Gidday JM: Cerebral preconditioning and ischaemic tolerance. Nat Rev Neurosci 7:437-448, 2006

18. Hammer MD, Krieger DW: Hypothermia for acute ischemic stroke: Not just another neuroprotectant. Neurologist 9:280-289, 2003

19. Hauck EF, Wei J, Quast MJ, Nauta HJ: A new technique allowing prolonged temporary cerebral artery occlusion. J Neurosurg 109:1127-1133, 2008

20. Heros RC, Nelson PB, Ojemann RG, Crowell RM, DeBrun G: Large and giant paraclinoid aneurysms: Surgical techniques, complications, and results. Neurosurgery 12:153-163, 1983

21. Hindman BJ, Bayman EO, Pfisterer WK, Torner JC, Todd MM: IHAST Investigators. No association between intraoperative hypothermia or supplemental protective drug and neurologic outcomes in patients undergoing temporary clipping during cerebral aneurysm surgery: Findings from the Intraoperative Hypothermia for Aneurysm Surgery Trial. Anesthesiology 112:86101,2010

22. Iwata O, Iwata S, Thornton JS, De Vita E, Bainbridge A, Herbert L, Scaravilli F, Peebles D, Wyatt JS, Cady EB, Robertson NJ: Therapeutic time window duration decreases with increasing severity of cerebral hypoxia-ischaemia under normothermia and delayed hypothermia in newborn piglets. Brain Res 1154:173180,2007

23. Jiang X, Shi E, Nakajima Y, Sato S: Postconditioning, a series of brief interruptions of early reperfusion, prevents neurologic injury after spinal cord ischemia. Ann Surg 244:148-153, 2006

24. Karabiyikoglu M, Han HS, Yenari MA, Steinberg GK: Attenuation of nitric oxide synthase isoform expression by mild hypothermia after focal cerebral ischemia: Variations depending on timing of cooling. J Neurosurg 98:1271-1276, 2003

25. Kirino T: Ischemic tolerance. J Cereb Blood Flow Metab 22:12831296, 2002 
26. Kitagawa K, Matsumoto $M$, Kuwabara K, Tagaya M, Ohtsuki T, Hata R, Ueda H, Handa N, Kimura K, Kamada T: 'Ischemic tolerance' phenomenon detected in various brain regions. Brain Res 561:203-211, 1991

27. Konstas AA, Choi JH, Pile-Spellman J: Neuroprotection for ischemic stroke using hypothermia. Neurocrit Care 4:168-178, 2006

28. Lavine SD, Masri LS, Levy ML, Giannotta SL: Temporary occlusion of the middle cerebral artery in intracranial aneurysm surgery: Time limitation and advantage of brain protection. J Neurosurg 87:817-824, 1997

29. Lazaris AM, Maheras AN, Vasdekis SN, Karkaletsis KG, Charalambopoulos A, Kakisis JD, Martikos G, Patapis P, Giamarellos-Bourboulis EJ, Karatzas GM, Liakakos TD: Protective effect of remote ischemic preconditioning in renal ischemia/reperfusion injury, in a model of thoracoabdominal aorta approach. Journal of Surgical Research 154:267-273, 2009

30. Lehotský J, Burda J, Danielisová V, Gottlieb M, Kaplán P, Saniová B: Ischemic tolerance: The mechanisms of neuroprotective strategy. Anat Rec (Hoboken) 292:2002-2012, 2009

31. Ljunggren B, Saveland H, Brandt L, Kagstrom E, Rehncrona S, Nilsson PE: Temporary clipping during early operation for ruptured aneurysm: Preliminary report. Neurosurgery 12:525-530, 1983

32. Mack WJ, Ducruet AF, Angevine PD, Komotar RJ, Shrebnick DB, Edwards NM, Smith CR, Heyer EJ, Monyero L, Connolly ES Jr, Solomon RA: Deep hypothermic circulatory arrest for complex cerebral aneurysms: lessons learned. Neurosurgery 60:815-827, 2007

33. McCord JM: Oxygen-derived free radicals in postischemic tissue injury. N Engl J Med 312:159-163, 1985

34. Mizoi K, Yoshimoto T: Permissible temporary occlusion time in aneurysm surgery as evaluated by evoked potential monitoring. Neurosurgery 33:434-440, 1992

35. Motoyama Y, Kawaguchi M, Yamada S, Nakagawa I, Nishimura F, Hironaka Y, Park YS, Hayashi H, Abe R, Nakase H: Evaluation of combined use of transcranial and direct cortical motor evoked potential monitoring during unruptured aneurysm surgery. Neurol Med Chir (Tokyo) 51(1):15-22, 2011

36. Murry CE, Jennings RB, Reimer KA: Preconditioning with ischemia: A delay of lethal cell injury in ischemic myocardium. Circulation 74:1124-1136, 1986

37. Nemethova M, Danielisova V, Gottlieb M, Kravcukova P, Burda J: Ischemic postconditioning in the rat hippocampus: Mapping of proteins involved in reversal of delayed neuronal death. Arch Ital Biol 148:23-32, 2010

38. Ogilvy CS, Carter BS, Kaplan S, Rich C, Crowell RM: Temporary vessel occlusion for aneurysm surgery: Risk factors for stroke in patients protected by induced hypothermia and hypertension and intravenous mannitol administration. J Neurosurg 84:785-791, 1996

39. Ohmoto T, Nagao S, Mino S, Fujiwara T, Honma Y, Ito T, Ohkawa M: Monitoring of cortical blood flow during temporary arterial occlusion in aneurysm surgery by the thermal diffusion method. Neurosurgery 28:49-55, 1991

40. Perez-Pinzon MA, Xu GP, Dietrich WD, Rosenthal M, Sick TJ: Rapid preconditioning protects rats against ischemic neuronal damage after 3 but not 7 days of reperfusion following global cerebral ischemia. J Cereb Blood Flow Metab 17: 175-182, 1997

41. Perez-Pinzon MA: Mechanisms of neuroprotection during ischemic preconditioning: Lessons from anoxic tolerance. Comp Biochem Physiol A Mol Integr Physiol 147:291-299, 2007
42. Ren C, Gao X, Niu G, Yan Z, Chen X, Zhao H: Delayed postconditioning protects against focal ischemic brain injury in rats. PLoS ONE 3(12):e3851, 2008

43. Rezkalla SH, Kloner RA: Preconditioning in humans. Heart Fail Rev 12:201-206, 2007

44. Samson D, Batjer HH, Bowman G, Mootz L, Krippner WJ, Meyer YJ, Allen BC: A clinical study of the parameters and effects of temporary arterial occlusion in the management of intracranial aneurysms. Neurosurgery 34:22-29, 1994

45. Sapolsky RM: Cellular defenses against excitotoxic insults. J Neurochem 76:1601-1611, 2001

46. Selman WR, Bhatti SU, Rosenstein CC, Lust WD, Ratcheson RA: Temporary vessel occlusion in spontaneously hypertensive and normotensive rats. Effect of single and multiple episodes on tissue metabolism and volume of infarction. J Neurosurg 80:1085-1090, 1994

47. Schurr A, Reid KH, Tseng MT, West C, Rigor BM: Adaptation of adult brain tissue to anoxia and hypoxia in vitro. Brain Res 374:244-248, 1986

48. Siesjö BK, Agardh CD, Bengtsson F: Free radicals and brain damage. Cerebrovasc Brain Metab Rev 1:165-211, 1989

49. Steinberg GK, Panahian N, Sun GH, Maier CM, Kunis D: Cerebral damage caused by interrupted, repeated arterial occlusion versus uninterrupted occlusion in a focal ischemic model. J Neurosurg 81: 554-559, 1994

50. Stenzel-Poore MP, Stevens SL, Xiong Z, Lessov NS, Harrington CA, Mori M, Meller R, Rosenzweig HL, Tobar E, Shaw TE, Chu $X$, Simon RP: Effect of ischaemic preconditioning on genomic response to cerebral ischaemia: Similarity to neuroprotective strategies in hibernation and hypoxia-tolerant states. Lancet 362:1028-1037, 2003

51. Sundt TM, Piepgras DG: Surgical approach to giant intracranial aneurysms. J Neurosurg 51:731-742, 1979

52. Suzuki J, Kwak R, Okudaira Y: The safe time limit of temporary clamping of cerebral arteries in the direct surgical treatment of intracranial aneurysm under moderate hypothermia. Tohoku J Exp Med 127:1-7, 1979

53. Symon L, Vajda J: Surgical experiences with giant intracranial aneurysms. J Neurosurg 61:1009-1028, 1984

54. Taskapilioglu MO, Alkan T, Goren B, Tureyen K, Sahin S, Taskapilioglu O, Korfali E: Neuronal protective effects of focal ischemic pre-and/or postconditioning on the model of transient focal cerebral ischemia in rats. J Clin Neurosci 16(5):693-697, 2009

55. Taylor CL, Selman WR, Kiefer SP, Ratcheson RA: Temporary vessel occlusion during intracranial aneurysm repair. Neurosurgery 39:893-905, 1996

56. Todd MM, Hindman BJ, Clarke WR, Torner JC; IHAST Investigators: Mild intraoperative hypothermia during surgery for intracranial aneurysm. N Engl J Med 352: 135- 145, 2005

57. Tomida S, Nowak TS Jr, Vass K, Lohr JM, Klatzo I: Experimental model for repetitive ischemic attacks in the gerbil: The cumulative effect of repeated ischemic insults. J Cereb Blood Flow Metab 7: 773-782, 1987

58. Turkkan A, Alkan T, Goren B, Kocaeli H, Akar E, Korfali E: Citicoline and postconditioning provides neuroprotection in a rat model of ischemic spinal cord injury. Acta Neurochir (Wien) 152:1033-1042, 2010 
59. Woertgen C, Rothoerl RD, Albert R, Schebesch KM, Ullrich OW: Effects of temporary clipping during aneurysm surgery. Neurol Res 30:542-546, 2008

60. Xing B, Chen H, Zhang M, Zhao D, Jiang R, Liu X, Zhang S: Ischemic postconditioning inhibits apoptosis after focal cerebral ischemia/reperfusion injury in the rat. Stroke 39:2362-2369, 2008

61. Zhao ZQ, Corvera JS, Halkos ME: Inhibition of myocardial injury by ischemic postconditioning during reperfusion: Comparison with ischemic preconditioning. Am J Physiol Heart Circ Physiol 285:579-588, 2003
62. Zhao H, Sapolsky RM, Steinberg GK: Interrupting reperfusion as a stroke therapy: Ischemic postconditioning reduces infarct size after focal ischemia in rats. J Cereb Blood Flow Metab 26:11141122, 2006

63. Zhao $\mathrm{H}$ : The protective effect of ischemic postconditioning against ischemic injury: From the heart to the brain. J Neuroimmune Pharmacol 2:313-318, 2008 